\title{
Engineering Carboxylic Acid Reductase (CAR) through A Whole-Cell Growth-Coupled NADPH Recycling Strategy
}

Levi Kramer, ${ }^{1}$ Xuan Le, ${ }^{1}$ Marisa Rodriguez, ${ }^{1}$ Mark A. Wilson, ${ }^{3}$ Jiantao Guo, ${ }^{2}$ and Wei Niu ${ }^{1 *}$

${ }^{1}$ Department of Chemical \& Biomolecular Engineering, University of Nebraska-Lincoln, Lincoln, Nebraska, 68588, United States.

2. Department of Chemistry, University of Nebraska-Lincoln, Lincoln, Nebraska, 68588, United States.

3. Department of Biochemistry, University of Nebraska-Lincoln, Lincoln, Nebraska, 68588, United States.

*To whom correspondence should be addressed: wniu2@unl.edu 


\section{Table of Contents}

Experimental.

Page 3

Supplemental Tables and Figures.

Table S1. Primers used in the study.

Page 6

Table S2. Mutant selection for the 2-methoxybenzoate substrate.

Page 7

Table S3. Mutant selection for the adipate substrate.

Page 8

Figure S1. Growth of wild-type E. coli strain in liquid media with and without benzoate.

Page 9

Figure S2. Growth of $E$. coli strains on solid media with and without benzoate.

Page 10

Figure S3. Growth of E. coli strains in liquid media with different carboxylates.

Page 11

Figure S4. Characterizations of MavCAR mutants from 2-methoxybenzoate selection.

Page 12

Figure S5. Characterizations of MavCAR mutants from adipate selection.

Page 13

Figure S6. Kinetic characterization of MavCAR variants on 6-hydroxyhexanoate.

Page 14

Figure S7. Protein expression analysis of adipate to 6-HHA 1,6-HDO conversion.

Page 15

References.

Page 16 


\section{Experimental.}

\section{General methods.}

All chemicals were of reagent grade or higher. All solutions were prepared in deionized water that was further treated by Barnstead Nanopure water purification system (Thermo Fisher Scientific). Lysogeny broth (LB) medium (1 L) contained Bacto tryptone (10 g), Bacto yeast extract $(5 \mathrm{~g})$, and $\mathrm{NaCl}(10 \mathrm{~g}) . \quad$ M9 salts $(1 \mathrm{~L})$ contained $\mathrm{Na}_{2} \mathrm{HPO}_{4}(6 \mathrm{~g}), \mathrm{KH}_{2} \mathrm{PO}_{4}(3 \mathrm{~g}), \mathrm{NH}_{4} \mathrm{Cl}(1 \mathrm{~g})$ and $\mathrm{NaCl}(0.5 \mathrm{~g})$. M9 glucose medium contained glucose $(10 \mathrm{~g} / \mathrm{L}), \mathrm{MgSO}_{4}(0.12 \mathrm{~g} / \mathrm{L}), \mathrm{CaCl}_{2}(0.028 \mathrm{~g} / \mathrm{L})$, thiamine hydrochloride $(0.001 \mathrm{~g})$ and trace metal $^{1}$ in $\mathrm{M} 9$ salts. M9 glucose agar plates were prepared by addition of Difco agar $(15 \mathrm{~g} / \mathrm{L})$ to the liquid medium. For whole-cell bioconversion experiments, adipic acid substrate was included in M9 glucose medium at a final concentration of $10 \mathrm{mM}$. The $\mathrm{pH}$ of the medium was adjusted to 7.0 with $\mathrm{KOH}$ prior to inoculation. Antibiotics were added where appropriate to following final concentrations: chloramphenicol (in methanol, $17 \mathrm{mg} / \mathrm{L})$, kanamycin (50 $\mathrm{mg} / \mathrm{L})$, ampicillin (100 mg/L). IPTG stock solution was added as necessary to the indicated final concentration. Carbon source, $\mathrm{MgSO}_{4}(1 \mathrm{M})$, and $\mathrm{CaCl}_{2}(0.5 \mathrm{M})$ solutions were autoclaved separately. Solutions of antibiotics, trace minerals, and IPTG were sterilized through $0.22 \mu \mathrm{m}$ membranes. Protein concentrations were determined by using the Bio-Rad Bradford protein assay kit (Bio-Rad Laboratories, Inc.). A Biotek Synergy HTX plate reader was used to record UV/Vis spectra and measurements of optical density at $600 \mathrm{~nm}\left(\mathrm{OD}_{600}\right)$.

\section{Strains and plasmids.}

The E. coli strain BW25113 (CGSC \#7636) was obtained from Coli Genetic Stock Center at Yale University. Deletion of the pgi and sthA genes from the genome of BW25113 were completed using a two-step scarless chromosomal modification method that relies on the $\lambda$ Red recombination system. ${ }^{2}$ The $s a c B$-encoded Bacillus subtilis levansucrase was used as the counterselection marker. ${ }^{3} \quad$ The genotype of obtained R- $\Delta 2$ strain was confirmed by DNA sequencing of the modified site. $\quad$ E. coli $\mathrm{NEB}^{\circledR}$ 5-alpha (New England Biolabs) was used as the host in molecular cloning experiments. E. coli GeneHogs ${ }^{\circledR}$ (Thermo Fisher Scientific) was used as the host in protein overexpression. Standard protocols were used for the construction, purification and analysis of plasmid DNA. $^{4}$ PCR amplifications were carried out using KOD Hot Start DNA polymerase (MilliporeSigma) by following the manufacturer's protocol. Primer synthesis and DNA sequencing services were provided by 
Eurofins MWG Operon. Sequences of all the primers that were used in this study are listed in Table S1.

Constructions of plasmids pZSC101-MavCAR-YahK and pZF-Sfp(Ni) were reported previously.

\section{Growth test of Escherichia coli strains.}

Single colonies of specified E. coli strains were cultured in LB media $(5 \mathrm{~mL})$ containing appropriate antibiotics overnight at $37^{\circ} \mathrm{C}$ with shaking at $250 \mathrm{rpm}$. An aliquot $(1 \mathrm{~mL})$ of the overnight culture was collected by centrifugation. After removal of the supernatant, the cells were first washed with M9 salts to remove residual media, then resuspended in equal volume of fresh M9 salts to produce the seed culture. Cell densities were determined by measurement of absorbance at $600 \mathrm{~nm}$. For growth tests in liquid media, appropriate volumes of the seed culture were introduced into $\mathrm{M} 9$ glucose media $(5 \mathrm{~mL})$ with or without a carboxylic acid substrate to reach an initial $\mathrm{OD}_{600}$ of 0.05 . IPTG at the concentration of $0.25 \mathrm{mM}$ was included in the liquid media when the expression of CAR enzymes was required. The cells were continuously cultured at $37{ }^{\circ} \mathrm{C}$ with shaking at 250

rpm. Samples were taken at indicated time points to monitor the cell growth. Triplicate cultures were included for each experiment. For growth tests on solid media, a $30 \mu \mathrm{L}$ of washed cells were spotted onto M9 glucose agar plates with or without a carboxylic acid substrate, then spread using sterile wood applicators. The plates were incubated at $37^{\circ} \mathrm{C}$. IPTG at the concentration of $0.25 \mathrm{mM}$ was included in the solid media when the expression of CAR enzymes was required. Cell growth was documented by taking pictures of the plates every $24 \mathrm{~h}$ using a BioRad Gel Doc XR+ system. Pictures shown are representatives of duplicate experiments.

\section{Expression and purification of CARs.}

Plasmids harboring the CAR mutants of interest were transformed into E. coli Genehogs strain along with plasmid pZF-Sfp(Ni). Obtained cells were cultured in LB medium with appropriate antibiotics at $37{ }^{\circ} \mathrm{C}$ with shaking at $250 \mathrm{rpm}$. Protein expression was induced with IPTG $(0.5 \mathrm{mM})$ when cell growth reached the exponential phase. Following an additional $16 \mathrm{~h}$ of cultivation at $30^{\circ} \mathrm{C}$, cells were harvested and lysed by sonication. After removal of the cell debris by centrifugation, cell-free lysate was applied to Ni Sepharose 6 Fast Flow resin (GE Healthcare) to purifiy CAR proteins with an $8 \mathrm{xHis}$ tag on the $\mathrm{C}$ terminus. Protein purifications followed the manufacturer's protocol. Purified proteins were dialyzed against a buffer that contained Tris- $\mathrm{HCl}(50 \mathrm{mM}, \mathrm{pH} 7.5)$, glycerol (10\%), dithiothreitol (DTT; $1 \mathrm{mM})$, and 
ethylenediaminetetraacetic acid (EDTA; $1 \mathrm{mM}$ ) prior to biochemical assays. Purities of obtained proteins were analyzed by SDS-PAGE.

\section{Whole-cell bioconversions.}

Wild-type E. coli strain MG1655 was transformed with plasmid pZF-Sfp(Ni) and pZSC101-MavCAR*-YahK that carried the wild-type or mutant CAR genes. A single colony was inoculated in LB medium $(5 \mathrm{~mL})$ with appropriate antibiotics and cultured overnight at $37^{\circ} \mathrm{C}$ with aeration at $250 \mathrm{rpm}$. An aliquot of the overnight culture $(1 \mathrm{~mL})$ was collected, washed and resuspended in an equal volume of M9 salts. A $50 \mu \mathrm{L}$ inoculation was transferred into M9 minimal media (5 mL, pH 7.0) containing glucose (10 g/L), IPTG (0.25 mM), adipic acid $(10 \mathrm{mM})$ and appropriate antibiotics in $30 \mathrm{~mL}$ culture tubes. Triplicate cultures of each strain were cultivated at $37^{\circ} \mathrm{C}$ with shaking at $250 \mathrm{rpm}$ for $24 \mathrm{~h}$. Harvested cells were centrifuged to obtained supernatant as the cellfree broth for sample preparation. Accumulation of 6-hydroxyhexanoic acid (6-HHA) and 1,6-hexanediol (1,6HDO) in adipate conversion experiments were analyzed and quantified by HPLC.

\section{Analytical methods.}

Product analysis by HPLC used an Agilent 1260 Infinity HPLC instrument (Agilent Technologies) equipped with an Aminex HPX-87H column (300x7.8 mm; Bio-Rad Laboratories). To prepare samples for analysis, cell-free broth was first mixed with internal standard (oxalic acid, $100 \mathrm{mM}$ ) at 95:5 (v/v) ratio, then filtered through a PTFE syringe filter $(0.2 \mu \mathrm{m})$. An aliquot $(10 \mu \mathrm{L})$ of the prepared sample was injected. Samples were eluted at $35^{\circ} \mathrm{C}$ with sulfuric acid $(5 \mathrm{mM}, 0.6 \mathrm{~mL} / \mathrm{min})$. Detection of adipic acid used a diode array detector at a

wavelength of $210 \mathrm{~nm}$. Detection of glucose, 6-HHA and 1,6-HDO used a refractive index detector. Retention times of analytes were the following: $9.0 \mathrm{~min}$ (glucose), $17.0 \mathrm{~min}$ (adipic acid), $26.2 \mathrm{~min}$ (6-HHA), and $43.9 \mathrm{~min}$ $(1,6-\mathrm{HDO})$. 


\section{Supplemental Tables and Figures.}

Table S1 Primers used in the study.

\begin{tabular}{|c|c|c|}
\hline Primers & Sequences (5'->3') & Usage \\
\hline Mav S274X F & aatgtggcgtcgtggtNNKaaaaattggtttggtgaaagcgca & S274 mutagenesis \\
\hline Mav S274X R & accacgacgecacattttacca & S274 mutagenesis \\
\hline Mav M296X F & tgccgatgagccatgttNNKggtcgtagcattctgtatggca & M296 mutagenesis \\
\hline Mav M296X R & aacatggctcatcggcatgaa & M296 mutagenesis \\
\hline Mav S299X F & agccatgttatgggtcgtNNKattctgtatggcaccetgggtaat & S299 mutagenesis \\
\hline Mav S299X R & acgacccataacatggctcat & S299 mutagenesis \\
\hline Mav N335X F & tcgtccgaccgaactgNNKtttgttccgegtatttgggaaaccct & N335 mutagenesis \\
\hline Mav N335X R & cagttcggtcggacgaaccagt & N335 mutagenesis \\
\hline Mav M389X F & tggtcgttttacctttgcaNNKaccggtagcgcaccgattagt & M389 mutagenesis \\
\hline Mav M389X R & tgcaaaggtaaaacgaccaccca & M389 mutagenesis \\
\hline Mav N276X R & tgctaccacgacgccacattttaccaacat & N276 mutagenesis \\
\hline Mav N276X F & tgtggcgtcgtggtagcaaaNNKtggtttggtgaaagcgcagca & N276 mutagenesis \\
\hline Mav W277X R & atttttgctaccacgacgccacattttac & W277 mutagenesis \\
\hline Mav W277X F & gtcgtggtagcaaaaatNNKtttggtgaaagcgcagcaagcatta & W277 mutagenesis \\
\hline Mav T390X R & cattgcaaaggtaaaacgaccacccagca & T390 mutagenesis \\
\hline Mav T390X F & gttttacctttgcaatgNNKggtagcgcaccgattagtccggaact & T390 mutagenesis \\
\hline Mav G391X R & gtcattgcaaaggtaaaacgaccaccca & G391 mutagenesis \\
\hline Mav G391X F & gttttacctttgcaatgaccNNKagcgcaccgattagtccggaact & G391 mutagenesis \\
\hline Mav V423X R & catacctgcttcggtgetaccatagcca & V423 mutagenesis \\
\hline Mav V423X F & agcaccgaagcaggtatgNNKctgtttgatggcgaaattcagcgt & V423 mutagenesis \\
\hline MavC-BamHI F & ttgcagcagcacagccggatc & Single-site plasmid cloning \\
\hline MavC-BamHI R & accagtgctgccggatccaca & Single-site plasmid cloning \\
\hline Mav NheI F & attcaattgtgagcggataacaatttcacacagaattca & Single-site plasmid cloning \\
\hline Mav NsiI R & tcggtgctaccatagccatccatcagat & Single-site plasmid cloning \\
\hline
\end{tabular}


Table S2. Mutant selection for the 2-methoxybenzoate substrate.

\begin{tabular}{|c|c|c|}
\hline Position & Mutation (\# of occurrences) ${ }^{a}$ & Total \# sequenced \\
\hline S274 & $\mathrm{n} / \mathrm{a}^{b}$ & 0 \\
\hline N276 & H (2), L (1) & 3 \\
\hline W277 & $\mathrm{G}(1), \mathrm{F}(1), \mathrm{W}(1)$ & 3 \\
\hline M296 & L (3) & 3 \\
\hline S299 & L (3), W (1), I (1) & 5 \\
\hline N335 & $\mathbf{V}(2), \mathbf{W}(1), \mathrm{I}(1)$ & 4 \\
\hline M389 & $\mathbf{W}(\mathbf{2}), \mathrm{F}(1)^{c}$ & 3 \\
\hline T390 & $\mathrm{n} / \mathrm{a}$ & 0 \\
\hline G391 & $\mathrm{n} / \mathrm{a}$ & 0 \\
\hline V423 & $\mathrm{n} / \mathrm{a}$ & 0 \\
\hline
\end{tabular}

a. Mutants in bold were kinetically characterized.

${ }^{b .} \mathrm{n} / \mathrm{a}$, not applicable. No colony with faster growth rate was detected.

c. The mutant has one additional point mutation. 
Table S3. Mutant selection for the adipate substrate.

\begin{tabular}{lll}
\hline Position & Mutation (\# of occurrences) $^{a}$ & Total \# sequenced $^{{ }^{2}}$ \\
S274 & n/a ${ }^{b}$ & 0 \\
N276 & P (2), R (1) & 3 \\
W277 & n/a & 0 \\
M296 & n/a & 0 \\
S299 & K (2), R (4) & 6 \\
N335 & R (8) & 8 \\
M389 & K (8) & 8 \\
T390 & G (2), A (1), L (1) & 4 \\
G391 & R (2), T (1), C (1) & 4 \\
V423 & n/a & 0 \\
\hline
\end{tabular}

a. Mutants in bold were kinetically characterized.

${ }^{b}$. $\mathrm{n} / \mathrm{a}$, not applicable. No colony with faster growth rate was detected.

${ }^{c}$. Mutants in red were false positives. 


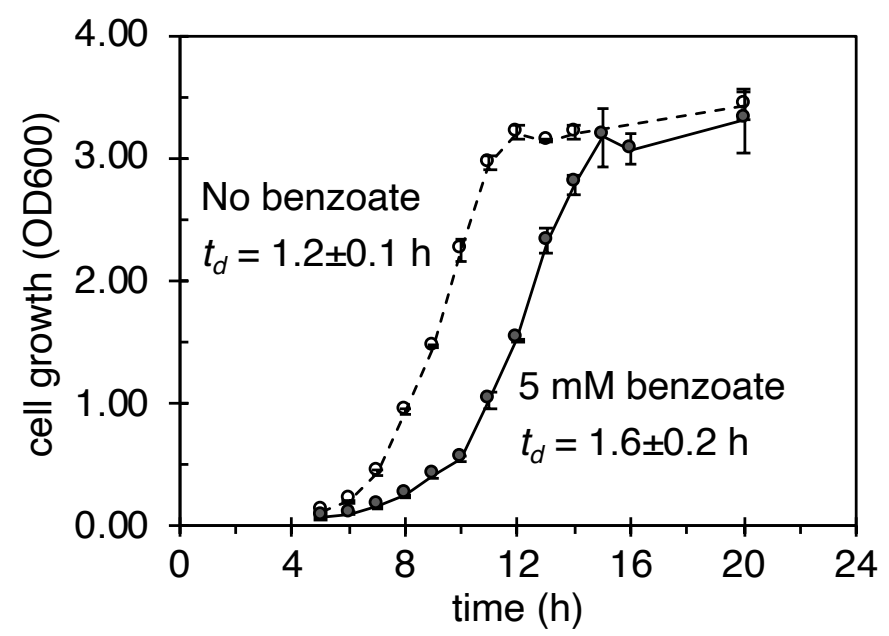

Figure S1. Growth of wild-type E. coli strain (BW25113) in liquid media with and without benzoate. Cells were cultured in M9 minimal media (1\% glucose) without and with benzoate $(5 \mathrm{mM})$. Data are the average of biological triplicates with standard deviations. 

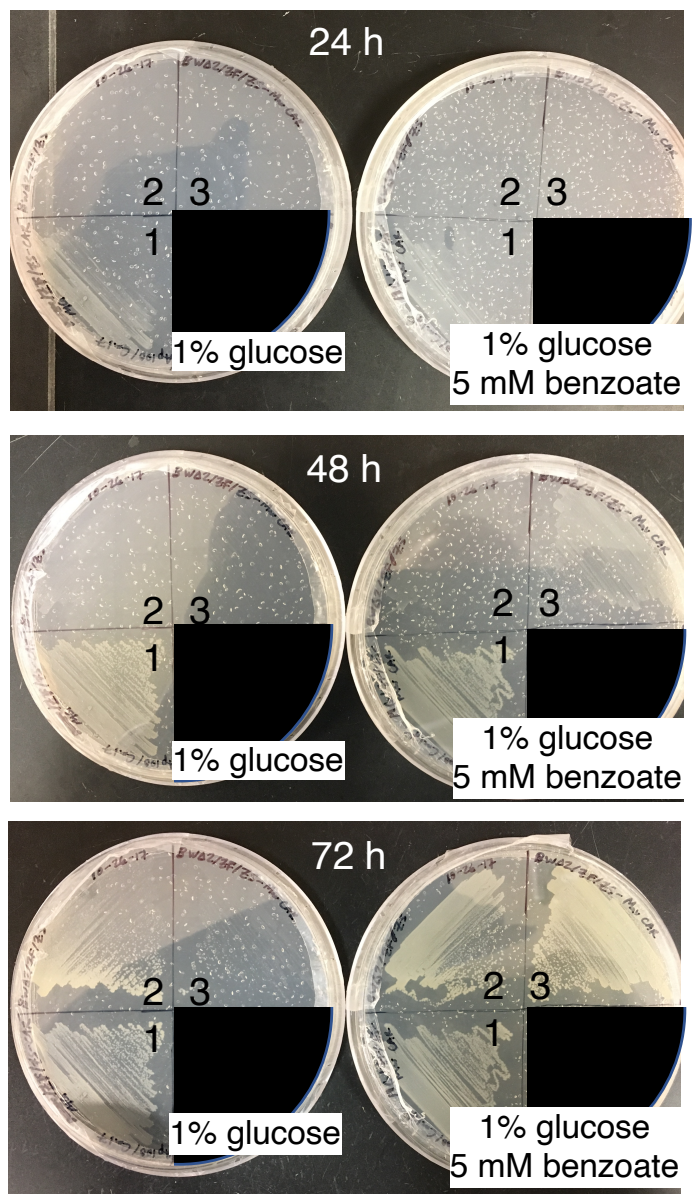

Figure S2. Growth of $\boldsymbol{E}$. coli strains on solid media with and without benzoate. Cells were streaked on M9 glucose $(1 \%)$ agar plates with or without $5 \mathrm{mM}$ benzoate. Plates were incubated at $37^{\circ} \mathrm{C}$. Pictures were taken at indicated time. All strains expressed the phosphopantetheinyl transferase (Sfp) from Nocardia iowensis. Strains: 1 , wild-type with empty vector; $2, \mathrm{R}-\Delta 2$ with empty vector; $3, \mathrm{R}-\Delta 2$ with MavCAR. Air bubbles formed in the agar during the course of incubation. 

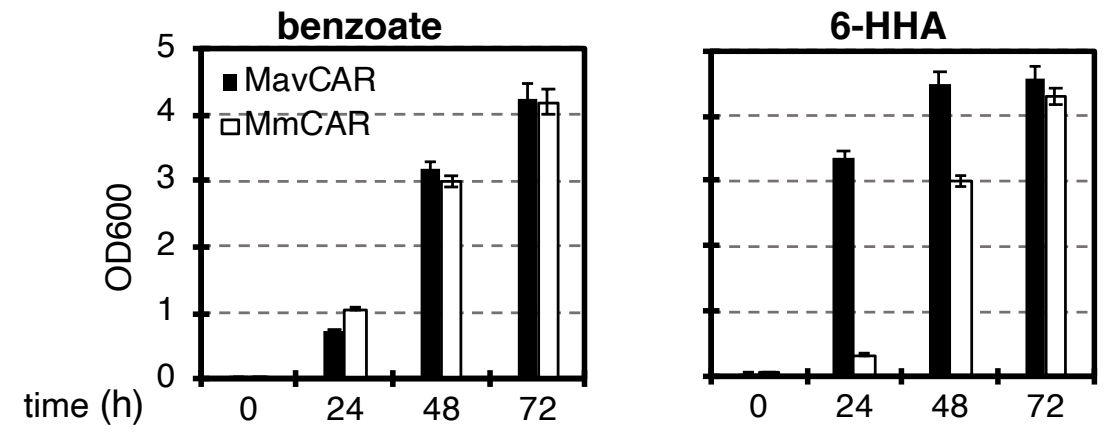

\begin{tabular}{ccccc}
\hline substrate & CAR & $K_{\mathrm{m}}(\mathrm{mM})$ & $k_{\text {cat }}\left(\mathrm{min}^{-1}\right)$ & $k_{\text {cat }} / K_{\mathrm{m}}\left(\mathrm{mM}^{-1} \mathrm{~min}^{-1}\right)$ \\
\hline \multirow{2}{*}{ benzoate } & MavCAR & $1.4 \pm 0.2$ & $242.1 \pm 14.0$ & $162.1 \pm 26.8$ \\
& MmCAR & $0.30 \pm 0.06$ & $35.5 \pm 1.4$ & $118.0 \pm 25.7$ \\
\hline \multirow{2}{*}{$6-\mathrm{HHA}$} & MavCAR & $10.0 \pm 1.4$ & $93.5 \pm 3.3$ & $9.3 \pm 1.4$ \\
& MmCAR & $22.9 \pm 3.3$ & $27.3 \pm 1.7$ & $1.2 \pm 0.2$ \\
\hline * .
\end{tabular}

Figure S3. Growth of $\boldsymbol{E}$. coli strains in liquid media with different carboxylates. R- $\Delta 2$ host expressed indicated CAR enzymes. Cells were cultured in M9 minimal media (1\% glucose) containing $10 \mathrm{mM}$ of carboxylate at $37{ }^{\circ} \mathrm{C}$ with aeration at $250 \mathrm{rpm}$. Cell densities were determined by measurement of absorbance at $600 \mathrm{~nm}(\mathrm{OD} 600)$. Data are the average of three measurements with standard deviations. 
A.

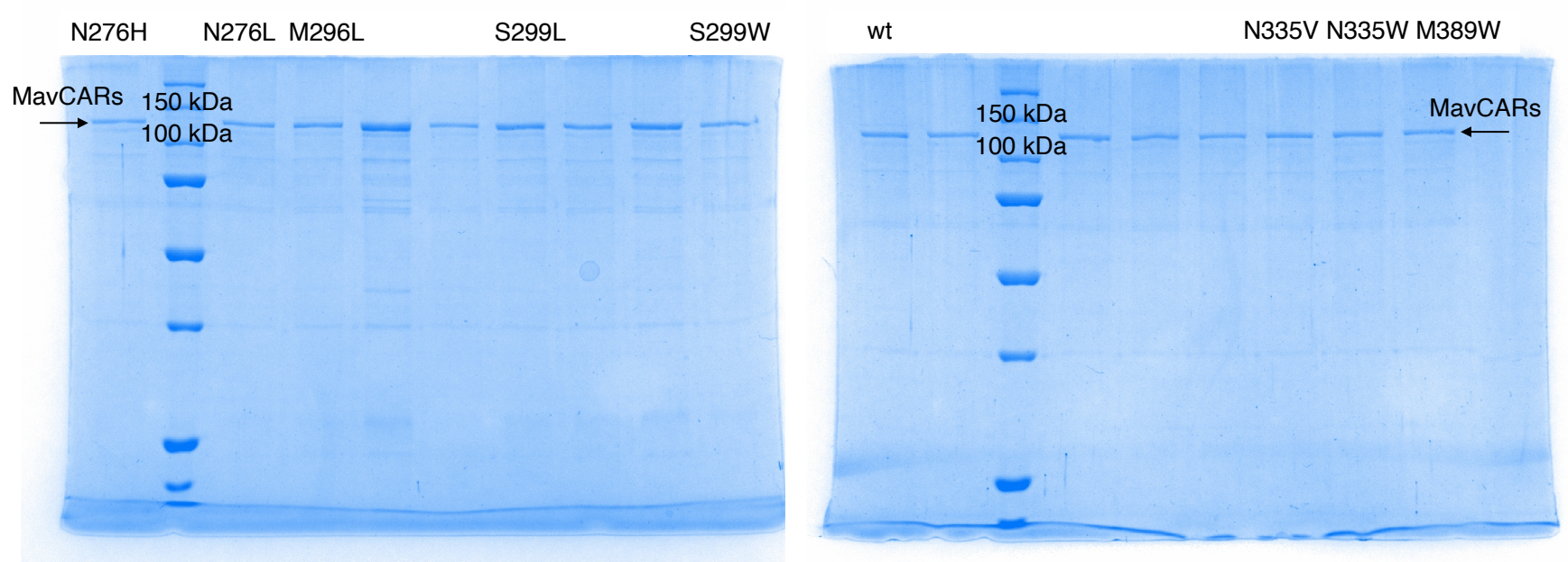

B.
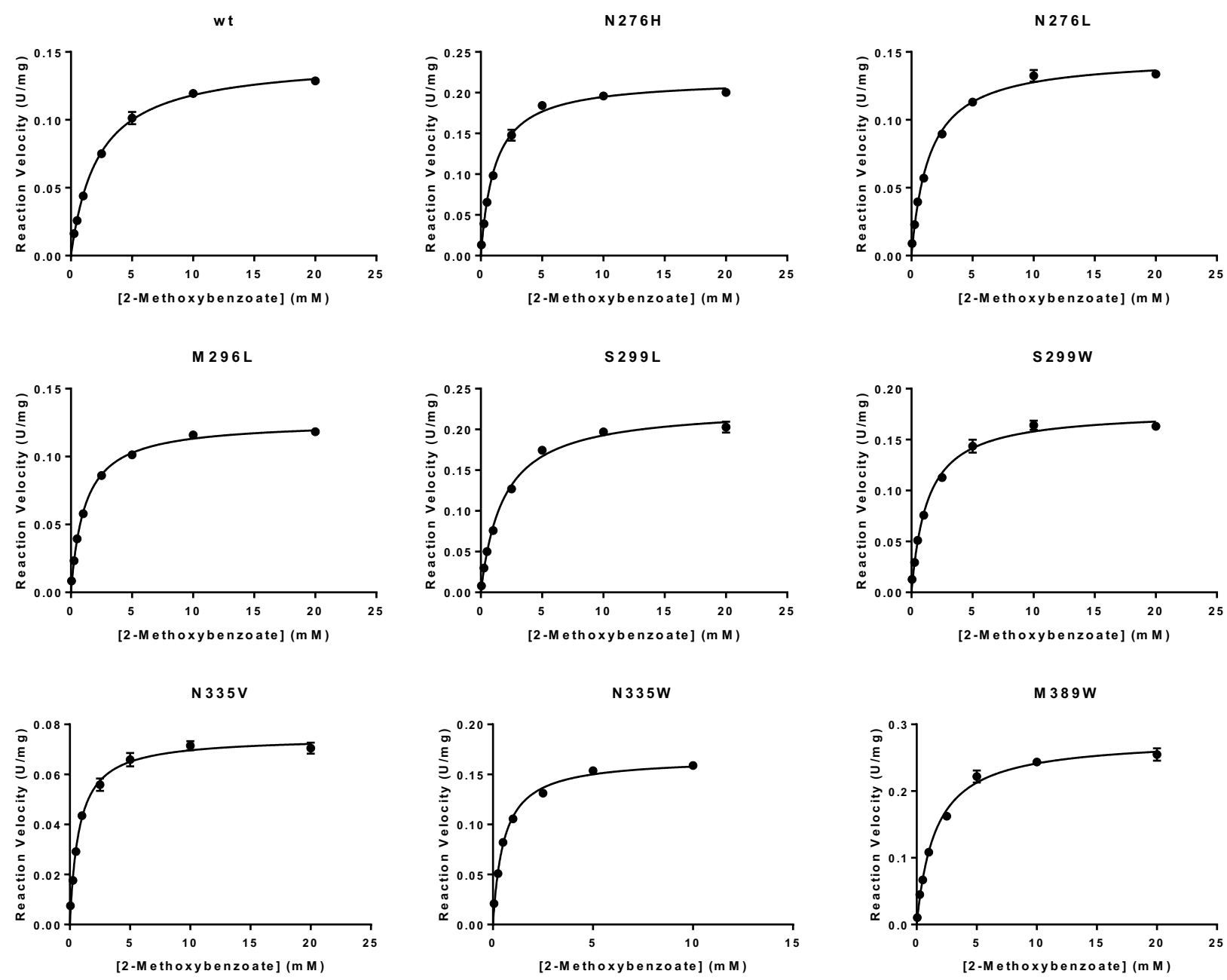

Figure S4. Characterization of MavCAR mutants from 2-methoxybenzoate selection. (A) SDS-PAGE of purified proteins. The MavCAR variants were purified as fusion proteins with an 8xHis tag on the $\mathrm{C}$ terminus. The predicted size of wild-type MavCAR is $129 \mathrm{kDa}$. A $0.5 \mathrm{ug}$ of purified protein was analyzed. Unlabeled lanes contain purified MavCAR variants from other selection experiments. (B) Michaelis-Menten plots of MavCAR variants on 2-methoxybenzoate substrate. 
A.

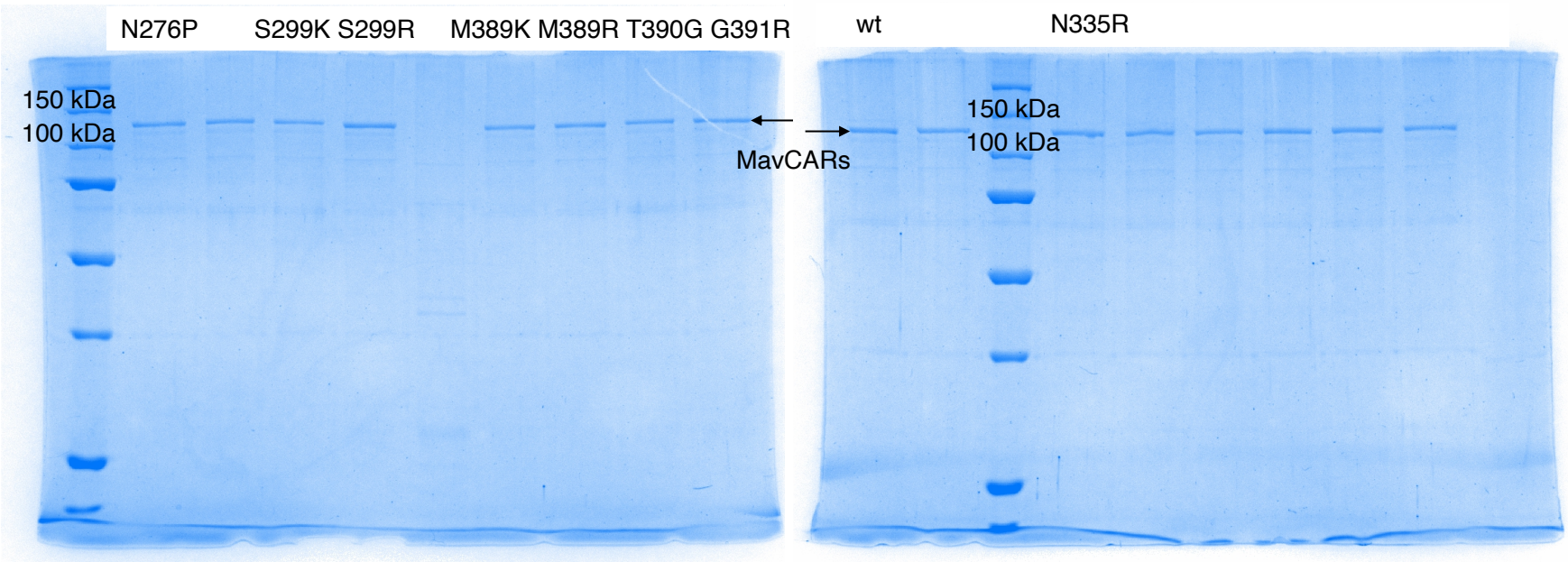

B.
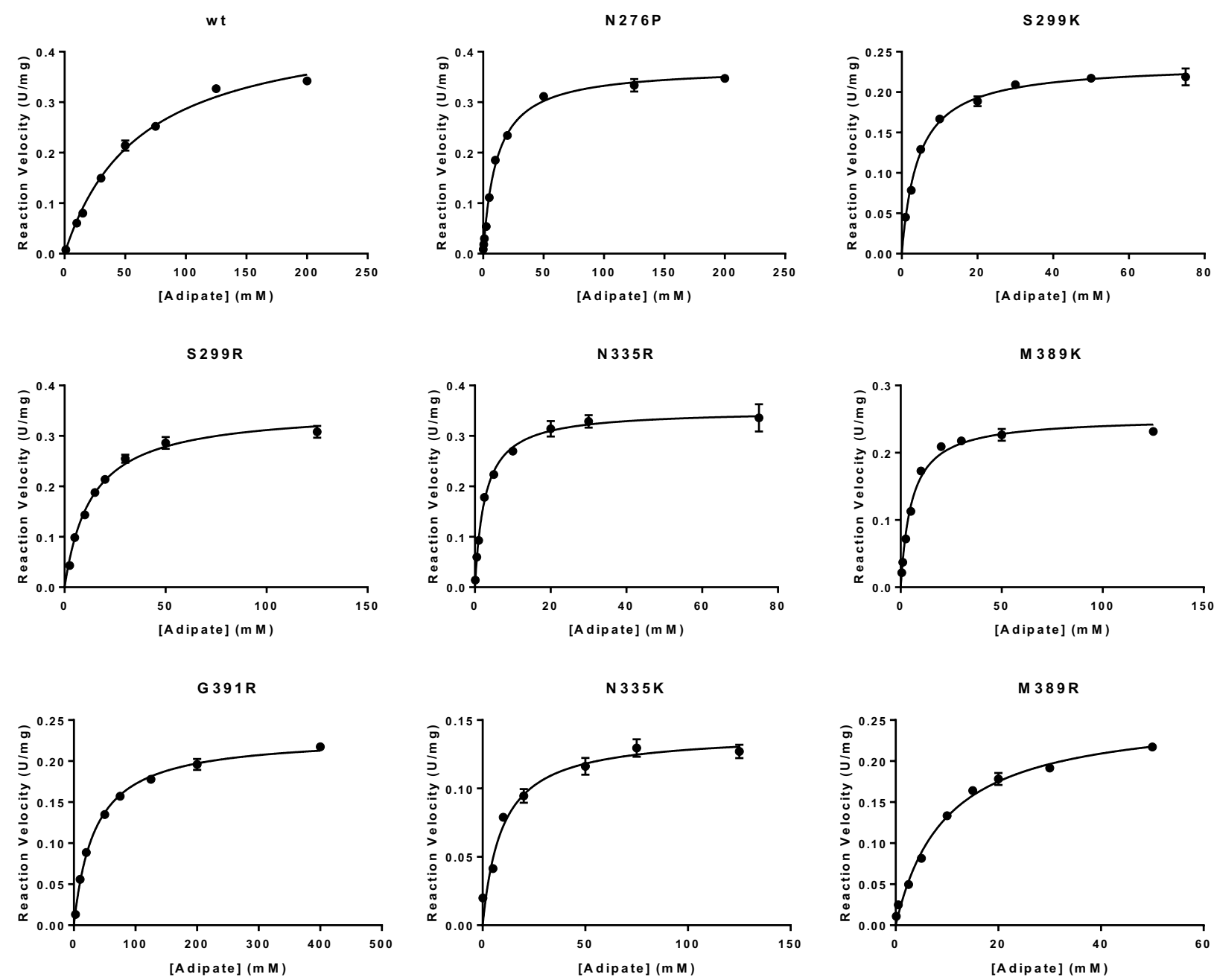

Figure S5. Characterization of MavCAR mutants from adipate selection. (A) SDS-PAGE of purified proteins. The MavCAR variants were purified as fusion proteins with an $8 \mathrm{xHis}$ tag on the $\mathrm{C}$ terminus. The predicted size of wild-type MavCAR is $129 \mathrm{kDa}$. A $0.5 \mathrm{ug}$ of purified protein was analyzed. Unlabeled lanes contain purified MavCAR variants from other selection experiments. (B) Michaelis-Menten plots of MavCAR variants on adipate substrate. 

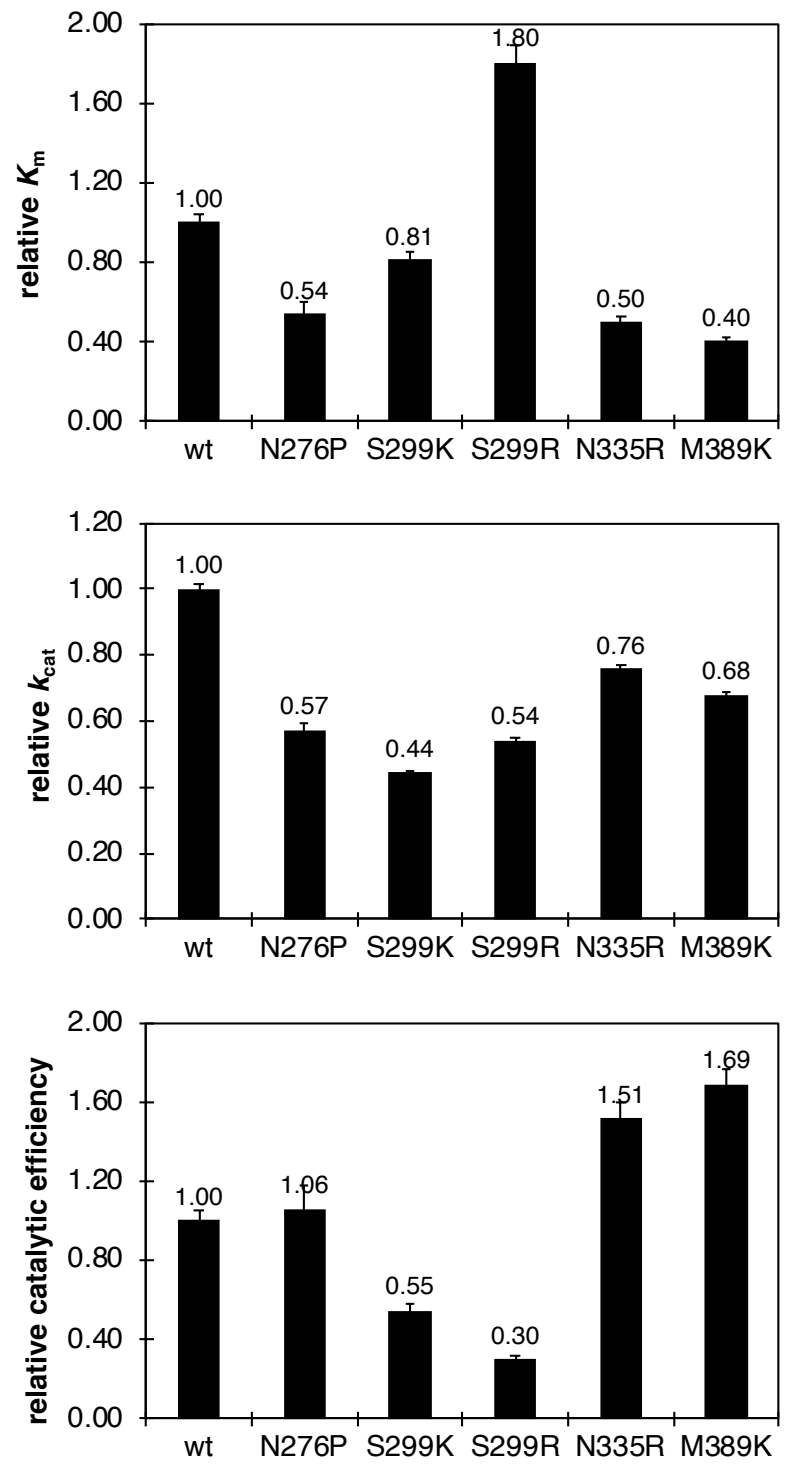

Figure S6. Kinetic characterization of MavCAR variants on 6-hydroxyhexanoic acid. The wild-type MavCAR has a $K_{\mathrm{m}}$ of $10.0 \pm 1.4 \mathrm{mM}$ and $k_{\text {cat }}$ of $93.5 \pm 3.3 \mathrm{~min}^{-1}$ on 6 -hydroxyhexanoic acid. ${ }^{5}$ Kinetic properties of MavCAR variants are expressed as relative values to the wild-type enzyme. 
wt N276R S299K S299R N335R M389K

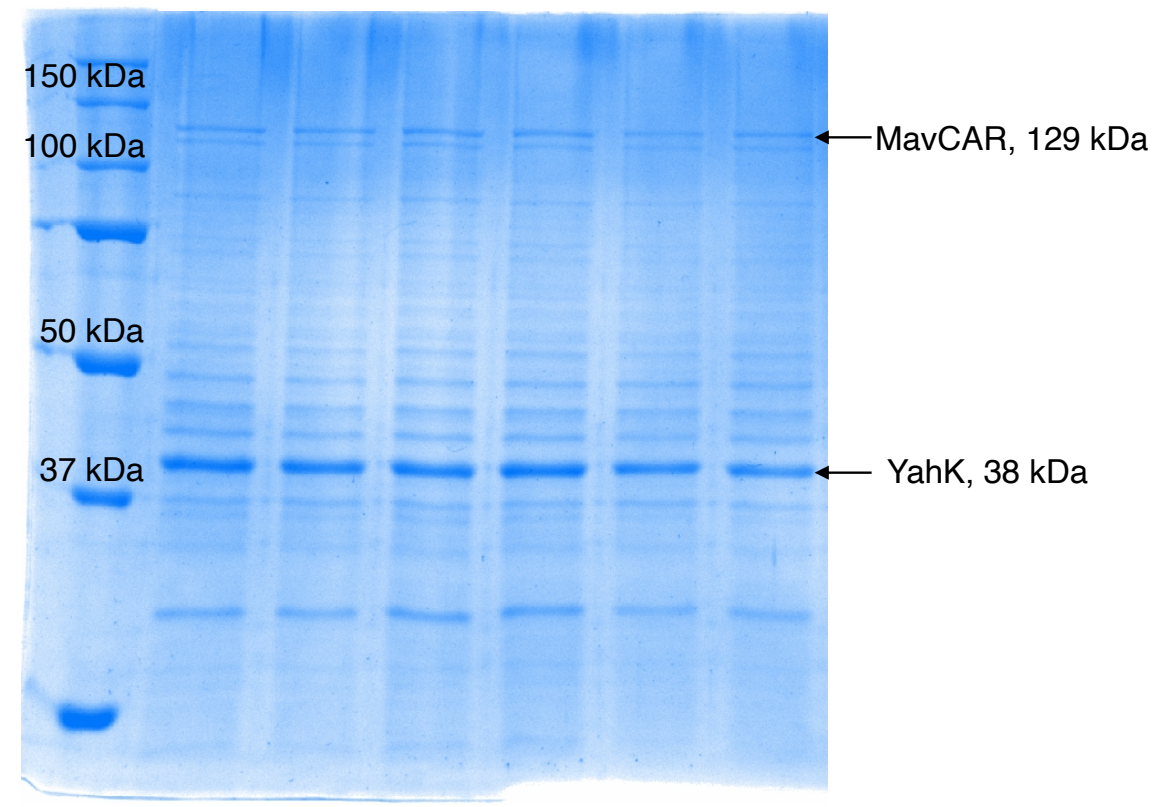

Figure S7. Protein expression analysis of adipate to 6-HHA and 1,6-HDO conversion. Cells from the bioconversion were collected and lysed. The total soluble protein fractions were analyzed by SDS-PAGE. 


\section{References.}

1. Studier, F. W., Protein production by auto-induction in high-density shaking cultures. Protein Expr. Purif. 2005, 41 (1), 207-234.

2. Zhang, Y.; Buchholz, F.; Muyrers, J. P. P.; Stewart, A. F., A new logic for DNA engineering using recombination in Escherichia coli. Nat. Genet. 1998, 20 (2), 123-128.

3. Edwards, R. A.; Keller, L. H.; Schifferli, D. M., Improved allelic exchange vectors and their use to analyze 987P fimbria gene expression. Gene 1998, 207 (2), 149-157.

4. Sambrook, J. F.; Russell, D. W.; Editors, Molecular cloning: A laboratory manual, third edition. Cold Spring Harbor Laboratory Press: 2000.

5. Kramer, L.; Hankore, E. D.; Liu, Y.; Liu, K.; Jimenez, E.; Guo, J.; Niu, W., Characterization of carboxylic acid reductases for biocatalytic synthesis of industrial chemicals. ChemBioChem 2018, 19 (13), 1452-1460. 